Novel transcript profiling of diffuse al veol ar danage i nduced by hyper oxi a exposure i $n$ mice: Nor mal i zat i on by gl ycer al dehyde 3 phosphate dehydr ogenase

\begin{tabular}{|c|c|}
\hline 著者 & $\begin{array}{l}\text { SHI NADA I chi roh, NATSUI Kazuhi r o, BRI NKMANN } \\
\text { Ber nd, HOHOFF Car st en, H RAGA Koi chi, TABUCH } \\
\text { Yoshi aki, TAKASAK I chi ro, KATO I chi ro, } \\
\text { KAWAGUCH H r oshi, TAKASAWA Kum, I I DA Rei ko, } \\
\text { TAK ZAWA H sao, MATSUKI Takasum }\end{array}$ \\
\hline $\begin{array}{l}\text { j our nal or } \\
\text { publ i cat } i \text { on } t i t l e\end{array}$ & I NTERNATI ONAL J OURNAL OF LEGAL MED CI NE \\
\hline vol une & 122 \\
\hline number & 5 \\
\hline page $r$ ange & $373-383$ \\
\hline year & 200809 \\
\hline URL & ht t p: //hdl . handl e. net /10098/2051 \\
\hline
\end{tabular}




\section{(1) Form of the paper}

Original Article

\section{(2) Title}

Novel transcript profiling of diffuse alveolar damage induced by hyperoxia exposure in mice: Normalization by glyceraldehyde 3-phosphate dehydrogenase

\section{(3) Authors}

Ichiroh Shimada · Kazuhiro Matsui · Bernd Brinkmann • Carsten Hohoff •

Koichi Hiraga · Yoshiaki Tabuchi · Ichiro Takasaki · Ichiro Kato · Hiroshi Kawaguchi •

Kumi Takasawa $\cdot$ Reiko Iida $\cdot$ Hisao Takizawa $\cdot$ Takasumi Matsuki

Ichiroh Shimada $\cdot$ Kazuhiro Matsui $\cdot$ Reiko Iida $\cdot$ Takasumi Matsuki

Department of Forensic Medicine, Faculty of Medical Sciences, University of Fukui, 23-3, Matsuokashimoaizuki, eiheiji-cho, Yoshida-gun, Fukui 910-1193, Japan 
Bernd Brinkmann · Carsten Hohoff

Institute of Legal Medicine, University of Münster, Röntgenstr. 23, 48149, Münster,

Germany

Koichi Hiraga $\cdot$ Ichiro Kato $\cdot$ Hiroshi Kawaguchi $\cdot$ Kumi Takasawa

Department of Biochemistry, Faculty of Medicine, University of Toyama, 2630

Sugitani, Toyama City, Toyama 930-0194, Japan

Yoshiaki Tabuchi · Ichiro Takasaki

Division of Molecular Genetics, Life Scientific Research Center, University of Toyama, 2630 Sugitani, Toyama City, Toyama 930-0194, Japan

Hisao Takizawa

Department of Legal Medicine, Faculty of Medicine, University of Toyama, 2630 Sugitani, Toyama-shi, Toyama 930-0194, Japan

(4) Corresponding Author's address 
Takasumi Matsuki

Department of Forensic Medicine,

Faculty of Medical Sciences,

University of Fukui,

23-3, Matsuokashimoaizuki, eiheiji-cho, Yoshida-gun, Fukui 910-1193, Japan

Tel: $\quad+81-776-61-8341$

Fax: $\quad+81-776-61-8108$

E-mail: ichi@u-fukui.ac.jp (I. Shimada) 


\section{Abstract}

Under mechanical ventilation with high-inspired oxygen concentration, diffuse alveolar damage (DAD) was found to take place in some patients. To clarify the molecular pathophysiology of this condition we investigated the time course of gene expression changes induced by hyperoxia exposure in mouse lung using real-time quantitative polymerase chain reaction (real-time qPCR). Our results normalized by glyceraldehyde 3-phosphate dehydrogenase showed that mRNA levels of cysteine rich protein 61 (CYR61) and connective tissue growth factor (CTGF) were significantly up-regulated, while those of surfactant-associated protein C (SFTPC), cytochrome P450, 2F2 (CYP2F2), Claudin 1, (CLDN1), membrane-associated zonula occludens protein-1 (ZO-1), lysozyme (LYZS), and P lysozyme structural (LZP-S) were significantly down-regulated. Increasing level of mRNAs, each encoding CYR61 and CTGF, suggests a serious risk of fibrosing alveolitis. Decrease in levels of mRNAs for SFTPC, CYP2F2, CLDN1, ZO-1, LYZS, and LZP-S suggests alveolar dysfunction and disruption of the immune system. Moreover we confirmed apoptotic conditions, such as significant up-regulations of mRNA levels in Myc and Galectin-3. Hyperoxic condition probably yielded reactive oxygen species (ROS), which resulted in a 
malignant cycle of ROS production by Myc overexpression.

\section{Keywords}

Diffuse alveolar damage ' Hyperoxia exposure ' Gene expression ' Myc •

Surfactant-associated protein C 


\section{Introduction}

Mechanical ventilation with high-inspired oxygen concentration is often used in care practices for critically ill patients after injury from wound or physical agents. Hyperoxia is a known cause of diffuse alveolar damage (DAD) [1], and it is sometimes identified upon judicial autopsy. For example, we have experienced cases of burn or misuse of respirator equipment, in which DAD was induced due to the association between prolonged use of highly concentrated oxygen and clinical disorders, that is, hypovolemic shock or bacterial pneumonia [2], respectively. We have posited toxic side effects of hyperoxia exposure in medicolegal expert opinions on these cases, however, we have required more objective evidence demonstrating the pathogenesis of DAD. Hyperoxia-exposure induced retinopathy of premature baby [3] has been previously taken into the law court in Japan. Forensically, we should check the toxic side effects of prolonged use of highly concentrated oxygen, in lung, too. We think that to clarify the molecular pathophysiology of hyperoxia-exposure induced lung injury is novel duty of our forensic pathologist as well as anesthesiologist.

Apart from hyperoxia exposure and mechanical ventilation [4], DAD could be caused by various etiology, including paraquat poisoning [5, 6], idiopathic causes [7, 
8], and non-thoracic trauma [9].

Histopathologically, DAD is characterized by the influx of protein-rich edema fluid into the air spaces as a consequence of increased permeability of the alveolar-capillary barrier [10]. Type I alveolar cells are easily injured, whereas type II alveolar cells appear to be more resistant in DAD. It is also well known that injury of vascular endothelial cell plays an important role in alveolar damage.

DAD is a disease which has a high mortality rate and leads to fibrosing alveolitis with persistent hypoxemia in serious cases. Improvement in the treatment of patients afflicted with it may have contributed to the recent decline in the mortality rate, however, the future therapeutic approach hopes to diminish inflammation of the alveolar vascular endothelium in the early stage, and to enhance the resolution of pulmonary edema [11].

Mice exposed to 90-95\% oxygen concentration die after 4 or 5 days with DAD [12]. Now novel transcript profiling technology including cDNA microarray and real-time qPCR allows the accurate measurement of changes in gene expression [13]. Therefore we examined the time course of gene expression changes using it. To date, no studies have been performed with regard to a comprehensive survey of gene expressions in DAD induced by hyperoxia exposure. 


\section{Materials and methods}

Animals and hyperoxia exposure

Eight-week-old mice (C57BL/6J, Charles River Japan, Inc.; NINOX Labo Supply Inc., Ishikawa, Japan) were purchased and acclimatized to a 12-h light / 12-h dark cycle starting at 8:00 and 20:00, respectively. Food and water were available ad libitum.

In the first experiment, we carried out cDNA microarray analysis. 8 male mice weighing 22-25g were randomly divided into two groups as follows: 1) 4 mice for control group were bred in atmospheric oxygen; 2) another 4 mice as the hyperoxia exposure group were bred in a metallic chamber for 2 days, into which oxygen, which was supplied from $100 \%$ oxygen concentration bomb, flowed at a rate of 0.8 liter $/ \mathrm{min}$. The oximeter (COSMOS XO-2000, New Cosmos Electric Co., Ltd, Japan) in the chamber indicated 90-95\% oxygen concentration.

In the second and third experiment, we carried out real-time qPCR analysis. 16 
male mice weighing 22-25g were randomly divided into 4 groups as follows: 1) 4 mice for control group were bred in atmospheric oxygen; 2) another 12 mice as the hyperoxia exposure group were bred in the metallic chamber for 1 day, 2 days, and 3 days, respectively.

At the end of these experiments, the mice were anesthetized with an intraperitoneal injection of Pentobarbital Sodium $(75 \mathrm{mg} / \mathrm{kg})$. Heparinized physiological phosphate saline buffer was infused into the left ventricle and blood was bled through the incised right atrium.

These animal experiments were approved by the Toyama Animal Care and Use Committee in University of Toyama (Toyama, Japan).

Histopathological analysis

The lung specimens were fixed in $10 \%$ formaldehyde buffered with PBS (pH 7.2) and then embedded with paraffin. $4 \mu \mathrm{m}$ tissue sections were prepared for Hematoxylin-Eosin stain or immunohistochemical staining.

The tissue sections were immunostained by the peroxidase method (EnVision System, DAKO Inc., Carpinteria, California) to evaluate the localization and degree of 
reactivity for a mouse monoclonal antibody against thyroid transcription factor-1 (TTF-1) (DAKO Inc., California; dilution 1 : 100) [14], nitric oxide synthase 2 (NOS2) (Santa Cruz biotechnology Inc., California; dilution 1 : 500), matrix metalloproteinase 2 (MMP2) (Santa Cruz biotechnology Inc., California; dilution 1 : 500), and Galectin-3 (Cedarlane Inc., Canada; dilution 1 : 250), respectively. Briefly, after deparaffinization the tissue sections were treated for antigen retrieval with tris buffer solution (TRS) in a wet chamber using microwaves, three times for 5 min each $[15,16]$. The sections were allowed to cool at room temperature for 30min. The sections were washed in TRS and sequentially treated with $3 \% \mathrm{H}_{2} \mathrm{O}_{2}$ for 15 min to exhaust endogenous peroxidase. After washing with TRS and blocking with 5\% normal horse serum for 30min, the sections were incubated with a primary antibody in a wet chamber using microwaves for $10 \mathrm{~min}$. After three washes with TRS, the peroxidase-labeled polymer from the EnVision System kit was applied for 10min in a wet chamber using microwaves. After washing in TRS, the color was developed with the Vector VIP substrate kit (Vector Laboratories, Burlingame, California), and the tissue sections were counterstained with Mayer's Hematoxylin.

For a negative control, each monoclonal antibody was replaced with normal mouse serum (DAKO Inc., Carpinteria, California). 
Measurement of inflammatory cells expressing Galectin-3

The number of alveolar macrophages and other inflammatory cells expressing

Galectin-3 was enumerated on 10-randomly chosen visual fields (magnification, $\quad \times$ 200) of the tissue sections stained with it. The statistical test of the average number of 10-microscopic fields was performed in SPSS ${ }^{\mathrm{TM}}$ (SPSS Japan Inc., Tokyo, Japan).

Separation of total RNA and mRNA

Total RNA was extracted from the lung using an RNeasy Protect Mini Kit (Qiagen Inc., Tokyo, Japan). It should be noted that total RNA samples were treated with RNase-Free DNase (Qiagen Inc., Tokyo, Japan) for 30min at room temperature.

mRNA was extracted from the DNase-treated sample using an GenElute ${ }^{\mathrm{TM}}$ mRNA Miniprep Kit (Sigma Inc., Saint Louis, USA) before cDNA microarray analysis was performed.

cDNA microarray analysis 
cDNA microarray analysis was performed by IntelliGene ${ }^{\mathrm{TM}}$ Mouse CHIP (Code No. X2021, Takara Shuzo Inc., Tokyo, Japan), which were spotted with 4277 cDNA fragments of mouse known genes. cDNA probes were prepared by reverse transcriptase reaction (RT reaction) (Omniscript Reverse Transcriptase, Qiagen Inc., Tokyo, Japan) with Cy3-dUTP (Amersham Pharmacia Biotech Inc., Tokyo, Japan) or Cy5-dUTP (Amersham Pharmacia Biotech Inc., Tokyo, Japan) and mRNA from the lung of both the control and hyperoxia exposure group, respectively, using an RNA Fluorescence Labeling Core Kit (Takara Shuzo Inc., Tokyo, Japan). In the first experiment, the control group was labeled with Cy3 and the hyperoxia exposure group was labeled with Cy5. In the second experiment, the control group was labeled with Cy5 and the hyperoxia exposure group was labeled with Cy3. Identical results were essentially expected. After treatment with RNase H, cDNA probes were purified by gel filtration. Hybridization and washing of the microarray were carried out according to the manufacturer's instructions. In brief, cDNA probe solutions containing both Cy3- and Cy5-labeled cDNA probes were applied to the microarrays, and then the microarrays were covered with a spaced glass cover slip (Takara Shuzo Inc., Tokyo, Japan) and placed in a humidified chamber at $65^{\circ} \mathrm{C}$ for $16 \mathrm{~h}$. Following this, the microarrays were 
sequentially washed in $2 \times \mathrm{SSC}(150 \mathrm{mM} \mathrm{NaCl}$ and $15 \mathrm{mM}$ sodium citrate) containing $0.2 \%$ SDS for $5 \mathrm{~min}$ twice at $55^{\circ} \mathrm{C}$, in $2 \times$ SSC containing $0.2 \%$ SDS for $5 \mathrm{~min}$ once at $65^{\circ} \mathrm{C}$, and in $0.05 \times$ SSC for $1 \mathrm{~min}$ once at room temperature. The microarrays were scanned in both Cy3 and Cy5 channels with a ScanArray Lite (Packard BioChip Technologies, Billerica, MA, USA). QuantArray software (Packard BioChip Technologies, USA) was used for image analysis. Genes were considered to be positively-expressed if the signal / background ratio was $>3.0$. The average of Cy3 and Cy5 signals for glyceraldehyde 3-phosphate dehydrogenase (GAPDH) (8 spots each) gave a ratio that was used to balance or normalize the signals.

Pathway analysis

To construct signal transduction pathway of DAD, up- and down- regulated genes from cDNA microarray analysis were analyzed using ingenuity pathway analysis ${ }^{\mathrm{TM}}$ (Ingenuity Systems, Inc., Redwood city, California, USA).

Real-time qPCR assay 
RT reaction (Omniscript Reverse Transcriptase, Qiagen Inc., Tokyo, Japan) was carried out with DNase-treated total RNA and an oligo $d(T)_{16}$ primer. Real-time qPCR was performed according to the manufacturer’s instructions for SYBR Premix Ex Taq ${ }^{\mathrm{TM}}$ (Takara Shuzo Inc., Tokyo, Japan) using the specific primers listed in Table 1. Amplification was performed by one round of pre-denaturation at $95^{\circ} \mathrm{C}$ for $10 \mathrm{sec}$, step-cycle mode of 40 rounds of denaturation at $95^{\circ} \mathrm{C}$ for $10 \mathrm{sec}$, annealing and extension at $60^{\circ} \mathrm{C}$ for 40sec. All reactions were performed in an Mx3000P (Stratagene Inc., La Jolla, USA). Fold change was normalized by the expression level of GAPDH.

Statistical analysis

The means, standard errors of the means (SEMs), and statistical analyses were calculated using SPSS ${ }^{\mathrm{TM}}$ (SPSS Japan Inc., Tokyo, Japan) in the present study. The unpaired Student's t-test was performed between the control ( $\mathrm{n}=10$ fields, Figs. $1 \mathrm{c}, \mathrm{e})$ and hyperoxia exposure group ( $\mathrm{n}=10$ fields, Figs. 1d, e) in histopathological analysis, conversely done between the control ( $\mathrm{n}=4$ mice, Figs. 2,3$)$ and hyperoxia exposure group ( $\mathrm{n}=4$ mice, Figs, 2, 3) in real-time qPCR assay. $\mathrm{P}$ values less than 0.05 were regarded as significant. 


\section{Results}

Histopathological findings

Histopathological findings together with Hematoxylin-Eosin stain and immunohistochemical staining with Galectin-3 in each group are shown in Fig. 1.

Histopathological findings depended on examination of the sample tissues from each of the lung lobes, and were found to be similar.

Hematoxylin-Eosin stain showed no significant difference between the control and the group of two-days' hyperoxia exposure (Figs. 1a, b). Immunohistochemical staining with TTF-1 antibody highlighted the nucleus of type II alveolar cells and Clara cells. It did not enable us to recognize distinct regenerative hyperplasia of type II alveolar cell. Immunohistochemical stainings with NOS2 and MMP2 showed no marked difference between the control and hyperoxia exposure groups.

However, immunohistochemical staining with Galectin-3 of the hyperoxia exposure group revealed that it was significantly expressed in alveolar macrophages 
and other inflammatory cells, compared with the control group (Figs. 1c, d, e).

cDNA microarray analysis

In order to assess expression of the genome-wide genes in DAD induced by hyperoxia exposure, we carried out cDNA microarray analysis of mouse lung.

Genes in which the averaged fold change was above 1.5 were listed in Table 2. These were 5 genes in 4277 genes analyzed, which were cysteine rich protein 61 (CYR61), ferritin light chain 1 (FTL1), connective tissue growth factor (CTGF), gamma actin, cytoplasmic 1 (Actg1), and solute carrier family 3, member 2 (Slc3a2). Whereas the averaged fold changes of 30 genes among those were below 0.67 . These were hemoglobin, beta adult major and minor chain (Hbb-b1 and Hbb-b2), surfactant-associated protein C (SFTPC), P lysozyme structural (LZP-S), lysozyme (LYZS), cytochrome P450, 2f2 (CYP2F2), and so on, as listed in Table 3.

This cDNA microarray doesn’t include Myc, Galectin-3, Occludin (OCLN), Claudin 1 and 18 (CLDN1 and CLDN18), and membrane-associated zonula occludens protein-1 (ZO-1). 
Time course of gene expression changes in real-time qPCR assay

We examined the time course of gene expression changes using real-time qPCR.

Fig. 2 showed the time course of gene expression changes in which the raw data were analyzed between the control and hyperoxia exposure group. GAPDH was significantly up-regulated when hyperoxia exposure was continued. In 3 days’ exposure, Myc, Galectin-3, CYR61, CTGF, and FTL1 were significantly up-regulated, while Hbb-b2, SFTPC, CYP2F2, CLDN1, ZO-1, LYZS, and LZP-S were significantly down-regulated.

Fig. 3 showed the time course of gene expression changes in which the data normalized by GAPDH were analyzed between the control and hyperoxia exposure group. Five genes including Myc, Galectin-3, CYR61, CTGF, and FTL1 were significantly up-regulated. Except for Galectin-3 and FTL1, the time courses had unidirectional tendencies. On the contrary, ten genes including Hbb-b1, Hbb-b2, SFTPC, CYP2F2, OCLN, CLDN 1 and 18, ZO-1, LYZS, and LZP-S were significantly down-regulated and mRNA levels decreased more and more when hyperoxia exposure was continued. 


\section{Discussion}

To clarify the molecular pathophysiology of DAD induced by hyperoxia exposure, we examined lungs of mice which were bred under high oxygen concentration for 1,2 , and 3 days. We used GAPDH to normalize the expression levels of the target mRNAs. The GAPDH was significantly up-regulated when hyperoxia exposure was continued (Fig. 2). Analysis of raw data (Fig. 2) and analysis of GAPDH-normalized data (Fig. 3) showed that twelve genes except for Hbb-b1, OCLN, and CLDN18 were similarly upor down-regulated in the second and third experiment of 3 days' exposure. The biological significance of these three genes requires confirmation by future analysis. We posit that other twelve results normalized by GAPDH have a biological significance in hyperoxia-induced DAD, because the time courses of expression changes for these genes had similar tendencies between the second and third experiment.

Histopathologically, Hematoxylin-Eosin stain and immunohistochemical staining with TTF-1, NOS2, and MMP2 showed no significant difference between the control and hyperoxia exposure groups.

However, immunohistochemical staining with Galectin-3 of the hyperoxia 
exposure group revealed that it was significantly expressed in alveolar macrophage and other inflammatory cells. Moreover, mRNA levels of Galectin-3 and Myc were significantly up-regulated in the hyperoxia exposure group. These imply undergoing apoptosis because Galectin-3 is an anti-apoptotic lectin that protects macrophages or $\mathrm{T}$ cells from death triggered by a variety of agents [17], and aberrant expression of Myc induces apoptosis [18].

Additionally, we assessed expression of the other genes which were selected from evidence of cDNA microarray analysis and its pathway analysis or articles on DAD. CYR61, CTGF, and FTL1 were significantly up-regulated, while Hbb-b2, SFTPC, CYP2F2, CLDN1, ZO-1, LYZS, and LZP-S were significantly down-regulated. The time courses of expression changes for these genes had unidirectional tendencies except for Galectin-3 and FTL1.

FTL1 encodes ferritin light chain 1 [19]. The functional molecule made of 24 identical subunits contains a central cavity, into which up to 4,500 insoluble iron ions is deposited. H-rich ferritins ( $\mathrm{H}$ subunit, molecular weight; 21,000) have been shown to accumulate or release iron faster than L-rich ferritins (L subunit, molecular weight; 19,000). Therefore, a greater proportion of $\mathrm{H}$ subunits is observed in erythropoietic tissue, and a greater proportion of L subunits is found in iron-storing tissue such as 
liver [20]. Sharkey et al. reported that initial serum ferritin elevation level correlated with the subsequent development of DAD [21]. Our result suggests the hyperfunction of reticulo-endothelial system due to process hemorrhaging which results from increased permeability of the alveolar-capillary barrier.

Hbb-b1 and Hbb-b2 exist in the cluster [22]. $\beta$-minor globin (Hbb-b2) gene expression is preferentially reduced in EKLF (erythroid Kruppel-like factor) knock-out mice and expression of the $\beta$-minor globin gene is more affected by EKLF deprivation than the $\beta$-major gene (Hbb-b1) [23]. This phenomenon is partially consistent with our observations, in which erythroid transcription factors such as EKLF appear to interact with the state of high oxygen concentration.

CYR61 plays essential roles in embryonic vascular development, while CTGF is secreted by vascular endothelial cells and promotes proliferation and differentiation of chondrocytes and enhances fibroblast growth factor-induced DNA synthesis. CTGF is expressed in advanced atherosclerotic lesions [24] or in renal fibrosis induced by hypoxia [25]. Bork proposed to group these genes under the denomination "CCN

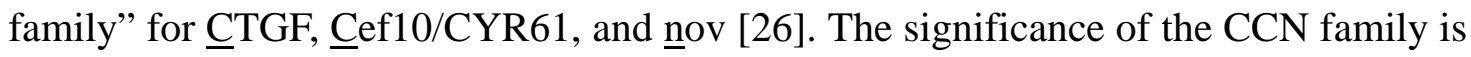
underscored by the finding that targeted disruptions of CCN1 (CYR61) and CCN2 (CTGF) both lead to lethality in mice. Both CCN1 and CCN2 promote a broad 
spectrum of cellular processes, including cell adhesion [27], migration, proliferation, and differentiation. Increasing levels of mRNAs each encoding CYR61 and CTGF suggest a serious risk for developing fibrosing alveolitis relevant to the inappropriate wound healing after DAD.

SFTPC encodes pulmonary surfactant-associated protein C (SP-C) [28], which promotes alveolar stability by lowering the surface tension at the air-liquid interface in the peripheral air spaces. Pulmonary surfactant consists of $90 \%$ lipid and $10 \%$ protein including four surfactant-associated protein: two hydrophilic carbohydrate-binding glycoproteins which are surfactant-associated protein A and D, and two small hydrophobic proteins which are surfactant-associated protein B and C. SP-C deficient mice develop a severe pulmonary disorder associated with atypical accumulations of intracellular lipids in type II alveolar cell, and emphysema [29]. Our result posits a serious risk for pulmonary collapse and emphysema.

CYP2F2 encodes the cytochrome P450 2F2; Naphthalene dehydrogenase, which belongs to the cytochromes P450 family and is a group of heme-thiolate monooxygenases [30]. This enzyme is involved in an NADPH-dependent electron transport pathway. It oxidizes a variety of structurally unrelated compounds, including steroids, fatty acids, and xenobiotics. Therefore, it catalyzes the production of a very 
potentially toxic intermediate that is associated with necrosis of type II alveolar cells and Clara cells. A decrease in level of mRNA for CYP2F2 implies a serious risk of pulmonary collapse because of loss of production for lung surfactants in these cells.

Alveolar-capillary barrier, composed of the alveolar epithelia and capillary endothelia, creates a selective barrier to water and solute flux between alveolar space and capillary. Especially, tight junctions regulate paracellular permeability of epithelia and endothelia. Recent reports have suggested that occludin (OCLN) may dimerize, forming a binding site for membrane-associated zonula occludens protein-1 (ZO-1), and ZO-1 connects occludin and claudins (CLDNs) to the cytoskeleton [31, 32]. These molecular weights are 65kDa (OCLN), 22 kDa (CLDN1), 29 kDa (CLDN 18), and $225 \mathrm{kDa}$ (ZO-1), respectively [33, 34]. Alterations in tight junctions occur the influx of protein-rich edema fluid into the air spaces. Decrease in levels of mRNAs for CLDN1 and ZO-1 suggests alveolar dysfunction, resulting from formation of hyaline membrane and collapsed alveoli.

And lysozymes (LYZS) encodes the lysozyme C, type M (milk); 1,4-beta-N-acetylmuramidase C. Mouse has two lysozyme Cs which are type M (milk) and type P (intestinal) (LZP-S) [35]. Lysozyme C is capable of hydrolysis of 1,4-beta-linkages between N-acetylmuramic acid and N-acetyl-D-glucosamine 
residues in peptidoglycan and between $\mathrm{N}$-acetyl-D-glucosamine residues in chitodextrins. In general, this enzyme is present in cytoplasmic granules of the polymorphonuclear neutrophils and has primarily a bacteriolytic function in tissues and body fluids such as tears and saliva. A decrease in levels of mRNAs for LYZS and LZP-S suggests a serious risk for progression of infection because of disruption of the immune system.

Physiologically, reactive oxygen species (ROS) are produced in the electron transport system of mitochondria or NADPH oxidase system of phagocytes. ROS play a crucial role in DAD induced by hyperoxia exposure and there is growing evidence that ROS induce cytokines [36]. A prior oxidative stress, including interleukin-1, can confer resistance or tolerance to subsequent oxidative stress [37, 38, 39]. Treatment with lisofylline inhibits hyperoxia-induced increase in tumor necrosis factor-alpha, interleukin-1 $\beta$, and interleukin-6 [40]. It is generally accepted that Myc overexpression can induce the production of ROS in mitochondria, leading to DNA damage and genomic instability such as gene amplification and polyploidy [41]. Our result that Myc was significantly up-regulated means that ROS produced by hyperoxia exposure induce Myc overexpression, and finally a malignant cycle of ROS production starts. ROS cause extreme damage to DNA or other cytoplasmic 
components, including the plasma membrane or the mitochondrial outer and inner membrane. It leads to morphologic changes of pulmonary vascular endothelia or alveolar epithelia, causing the influx of protein-rich edema fluid into the air spaces in turn.

In conclusion, the mRNA levels of Myc, Galectin-3, CYR61, CTGF and FTL1 were significantly up-regulated, while those of Hbb-b2, SFTPC, CYP2F2, CLDN1, ZO-1, LYZS, and LZP-S were significantly down-regulated in DAD induced by hyperoxia exposure. Up-regulations of CYR61 and CTGF suggest a serious risk for fibrosing alveolitis. Down-regulations of SFTPC, CYP2F2, CLDN1, ZO-1, LYZS, and LZP-S mean alveolar dysfunction and disruption of the immune system. Overexpression of Myc and Galectin-3 implies the onset of apoptosis. Especially, Myc overexpression means a malignant cycle of ROS production in lung. Our present results regarding changes in gene expressions will provide a novel finding in pathogenesis of DAD and open up new avenues for therapeutic intervention.

\section{Acknowledgements}

This study was supported in part by a Grants-in-Aid for Scientific Research from 
the Japanese Ministry of Education, Culture, Sports, Science, and Technology: Scientific Research (C) No. 17590574. The authors would like to thank Tomoko Kitayama for their excellent technical assistance. 


\section{References}

[1] Ichikado K, Suga M, Gushima Y, Johkoh T, Iyonaga K, Yokoyama T, Honda O, Shigeto Y, Tomiguchi S, Takahashi M, Itoh H, Ikezoe J, Müller NL, Ando M (2000) Hyperoxia-induced diffuse alveolar damage in pigs: correlation between thin-section CT and histopathologic findings. Radiology 216(2):531-538

[2] Zhou Z, Kozlowski J, Schuster DP (2005) Physiologic, biochemical, and imaging characterization of acute lung injury in mice. Am J Respir Crit Care Med $172: 344-351$

[3] Wright KW, Sami D, Thompson L, Ramanathan R, Joseph R, Farzavandi S (2006) A physiologic reduced oxygen protocol decreases the incidence of threshold retinopathy of prematurity. Trans Am Ophthalmol Soc 104:78-84

[4] Ikegaki J, Mikawa K, Obara H (1993) Effects of surfactant on lung injury induced by hyperoxia and mechanical ventilation in rabbits. J Anesth 7:66-74

[5] Ishida Y, Takayasu T, Kimura A, Hayashi T, Kakimoto N, Miyashita T, Kondo T (2006) Gene expression of cytokines and growth factors in the lungs after paraquat administration in mice. Legal Med 8:102-109

[6] Orito K, Suzuki Y, Matsuda H, Shirai M, Akahori F (2004) Chymase is activated in the pulmonary inflammation and fibrosis induced by paraquat in hamsters. Tohoku 
J Exp Med 203:287-294

[7] Katzenstein AA, Myers JL (1998) Idiopathic pulmonary fibrosis. Am J Respir Crit Care Med 157:1301-1315

[8] Chilosi M, Poletti V, Zamo A, Lestani M, Montagna L, Piccoli P, Pedron S, Bertaso M, Scarpa A, Murer B, Cancellieri A, Maestro R, Semenzato G., Doglioni C (2003) Aberrant Wnt/ $\beta$-catenin pathway activation in idiopathic pulmonary fibrosis. Am J Pathol 162:1495-1502

[9] Dechert RE. The pathophysiology of acute respiratory distress syndrome (2003) Respir Care Clin N Am 9(3):283-296

[10] Ware LB, Matthay MA (2000) The acute respiratory distress syndrome. N Engl J Med 342(18):1334-1349

[11] Geiser T (2003) Mechanisms of alveolar epithelial repair in acute lung injury - a translational approach. Swiss Med Wkly 133:586-590

[12] Barazzone C, Horowitz S, Donati YR, Rodriguez I, Piguet P-F (1998) Oxygen toxicity in mouse lung: pathways to cell death. Am J Respir Cell Mol Biol 19(4):573-581

[13] Tabuchi Y, Kondo T, Suzuki Y, Obinata M (2005) Genes involved in nonpermissive temperature-induced cell differentiation in Sertoli TTE3 cells 
bearing temperature-sensitive simian virus 40 large T-antigen. Biochem Biophys Res Commun 329:947-956

[14] Holzinger A, Dingle S, Bejarano PA, Miller MA, Weaver TE, Dilauro R, Whitsett JA (1996) Monoclonal antibody to thyroid transcription factor-1: production, characterization, and usefulness in tumor diagnosis. Hybridoma 15(1):49-53

[15] Kumada T, Tsuneyama K, Hatta H, Ishizawa S, Takano Y (2004) Improved 1-h rapid immunostaining method using intermittent microwave irradiation: practicability based on 5 years application in Toyama Medical and Pharmaceutical University Hospital. Modern Pathology 17:1141-1149

[16] Tatsu K, Hayashi S, Shimada I, Matsui K (2005) Cyclooxygenase-2 in sporadic colorectal polyps: Immunohistochemical study and its importance in the early stages of colorectal tumorigenesis. Pathology-Research and Practice 201:427-433

[17] Hoyer KK, Pang M, Gui D, Shintaku IP, Kuwabara I, Liu F-T, Said JW, Baum LG, Teitell MA (2004) An anti-apoptotic role for Galectin-3 in diffuse large B-cell lymphomas. Am J Pathol 164(3):893-902

[18] Sears RC, Nevins JR (2002) Signaling networks that link cell proliferation and cell fate. J Biol Chem 277(14):11617-11620

[19] Renaudie F, Boulanger L, Grandchamp B, Beaumont C (1995) Cloning, 
characterization and expression of mouse ferritin L subunit gene. C R Acad Sci III 318(4):431-437

[20] Beaumont C, Dugast I, Renaudie F, Souroujon M, Grandchamp B (1989) Transcriptional regulation of ferritin $\mathrm{H}$ and $\mathrm{L}$ subunits in adult erythroid and liver cells from the mouse. J Biol Chem 264(13):7498-7504

[21] Sharkey RA, Donnelly SC, Connelly KG, Robertson CE, Haslett C, Repine JE (1999) Initial serum ferritin levels in patients with multiple trauma and the subsequent development of acute respiratory distress syndrome. Am J Respir Crit Care Med 159(5),1506-1509

[22] Jahn CL, Hutchison CA, Phillips SJ, Weaver S, Haigwood NL, Voliva CF, Edgell MH (1980) DNA sequence organization of the $\beta$-globin complex in the BALB/c mouse. Cell 21(1):159-168

[23] Porcu S, Poddie D, Melis M, Cao A, Ristaldi MS (2005) $\beta$-minor globin gene expression is preferentially reduced in EKLF knock-out mice. Gene 351:11-17

[24] Oemar BS, Werner A, Garnier J-M, Do D-D, Godoy N, Nauck M, Marz W, Rupp J, Pech M, Luscher TF (1997) Human connective tissue growth factor is expressed in advanced atherosclerotic lesions. Circulation 95:831-839

[25] Higgins DF, Biju MP, Akai Y, Wutz A, Johnson RS, Haase VH (2004) Hypoxic 
induction of Ctgf is directly mediated by Hif-1. Am J Physiol Renal Physiol 287:1223-1232

[26] Bork P (1993) The modular architecture of a new family of growth regulators related to connective tissue growth factor. FEBS 327(2):125-130

[27] Chen C-C, Chen N, Lau LF (2001) The angiogenic factors Cyr61 and connective tissue growth factor induce adhesive signaling in primary human skin fibroblasts. $\mathrm{J}$ Biol Chem 276(13):10443-10452

[28] Glasser SW, Korfhagen TR, Bruno MD, Dey C, Whitsett JA (1990) Structure and expression of the pulmonary surfactant protein SP-C gene in the mouse. J Biol Chem 265(35):21986-21991

[29] Glasser SW, Detmer EA, Ikegami M, Na C-L, Stahlman MT, Whitsett JA (2003) Pneumonitis and emphysema in sp-C gene targeted mice. $\mathrm{J}$ Biol Chem 278(16):14291-14298

[30] Ritter JK, Owens IS, Negishi M, Nagata K, Sheen YY, Gillette JR, Sasame HA (1991) Mouse pulmonary cytochrome P-450 naphthalene hydroxylase: cDNA cloning, sequence, and expression in Saccharomyces cerevisiae. Biochemistry 30(48):11430-11437 
[31] Felinski EA, Antonetti DA (2005) Glucocorticoid regulation of endothelial cell tight junction gene expression: novel treatments for diabetic retinopathy. Current Eye Research 30:949-957

[32] Wu S, Lim K-C, Huang J, Saidi RF, Sears CL (1998) Bacteroides fragilis enterotoxin cleaves the zonula adherens protein, E-cadherin. Proc Natl Acad Sci 95:14979-14984

[33] Morita K, Furuse M, Fujimoto K, Tsukita S (1999) Claudin multigene family encoding four-transmembrane domain protein components of tight junction strands. Proc Natl Acad Sci 96:511-516

[34] Willott E, Balda MS, Heintzelman M, Jameson B, Anderson JM (1992) Localization and differential expression of two isoforms of the tight junction protein ZO-1. Am J Physiol 262(5 Pt 1):C1119-C1124

[35] Cross M, Renkawitz R (1990) Repetitive sequence involvement in the duplication and divergence of mouse lysozyme genes. EMBO J 9 (4):1283-1288

[36] Behr J, Maier K, Krombach F, Adelmann-Grill BC (1991) Pathogenetic significance of reactive oxygen species in diffuse fibrosing alveolitis. Am Rev Respir Dis 144(1):146-150

[37] Faust-Chan R, Hybertson B, Flores SC, Wright RM, Repine JE (1999) Initiation 
and tolerance to acute lung injury: Yin-Yang mechanisms involving interleukin-1.

Chest 116:102S-103S

[38] Brown JM, White CW, Terada LS, Grosso M, Shanley PF, Mulvin DW, Banerjee A, Whitman GJR, Harken AH, Repine JE (1990) Interleukin 1 pretreatment decreases ischemia/reperfusion injury. Proc Natl Acad Sci 87:5026-5030

[39] White CW, Ghezzi P, Dinarello CA, Caldwell SA, McMurtry IF, Repine JE (1987) Recombinant tumor necrosis factor/cachectin and interleukin 1 pretreatment decreases lung oxidized glutathione accumulation, lung injury, and mortality in rats exposed to hyperoxia. J Clin Invest 79:1868-1873

[40] George CLS, Fantuzzi G., Bursten S, Leer L, Abraham E (1999) Effects of lisofylline on hyperoxia-induced lung injury. Am J Physiol Lung 276:776-785

[41] Thompson EB. The many roles of c-Myc in apoptosis (1998) Annu Rev Physiol $60: 575-600$ 


\section{Legends to Figures}

Fig. 1

Hematoxylin-Eosin stain of the control group (a) and the group of two-days' hyperoxia exposure (b), in the lung tissues from mice. It showed no significant difference between the control and hyperoxia exposure groups.

Immunohistochemical staining with Galectin-3 of the control group (c) and the group of two-days' hyperoxia exposure (d), in the lung tissues from mice. The hyperoxia exposure group revealed that it was significantly expressed in alveolar macrophages and other inflammatory cells, compared with the control group.

The number of cells expressing Galectin-3 is enumerated on 10-randomly chosen visual fields (magnification, $\times 200$ ) of the tissue sections stained with Galectin-3 (e). Bars show means and error bars show standard errors of the means (SEMs). Unpaired Student's t-test is performed between the control and hyperoxia exposure groups. $\mathrm{P}$ value was less than $0.001(* * * \mathrm{p}<0.001)$.

Fig. 2

Time course of gene expression changes in DAD induced by hyperoxia exposure. 
White and black bars show data of the second and third experiment, respectively. The raw data are analyzed between the control and hyperoxia exposure group. Each of fold changes for hyperoxia exposure groups was divided by averages of those for the control groups. Accordingly, fold change indicates 1.0 if data for both the control and hyperoxia exposure groups are same. Bars show means and error bars show standard errors of the means (SEMs). Unpaired Student's t-test is performed between the control and hyperoxia exposure groups. $\mathrm{P}$ values less than 0.05 are regarded as significant: ${ }^{*} \mathrm{p}<0.05,{ }^{* *} \mathrm{p}<0.01,{ }^{* * *} \mathrm{p}<0.001$. mRNA level for GAPDH is significantly up-regulated when hyperoxia exposure is continued. In 3 days’ exposure, Myc, Galectin-3, CYR61, CTGF, and FTL1 are significantly up-regulated, while Hbb-b2, SFTPC, CYP2F2, CLDN1, ZO-1, LYZS, and LZP-S are significantly down-regulated.

Fig. 3

Time course of gene expression changes in DAD induced by hyperoxia exposure. White and black bars show data of the second and third experiment, respectively, as Fig. 2. The data normalized by GAPDH are analyzed between the control and hyperoxia exposure groups. mRNA levels for five genes including Myc, Galectin-3, CYR61, CTGF, and FTL1 are significantly up-regulated. Whereas mRNA levels for ten genes 
including Hbb-b1, Hbb-b2, SFTPC, CYP2F2, OCLN, CLDN 1 and 18, ZO-1, LYZS, and LZP-S are significantly down-regulated. 


\section{Control}
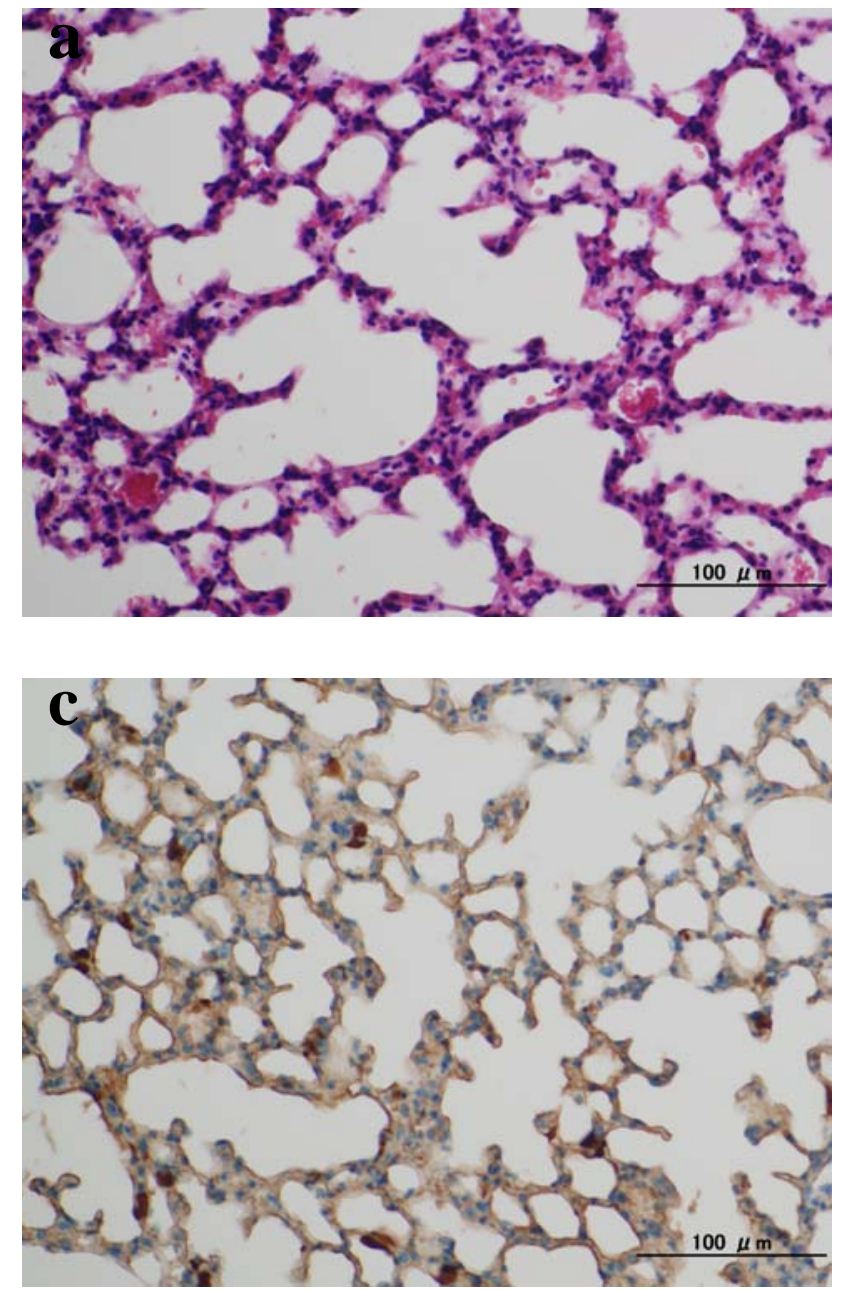

\section{Hyperoxia exposure}
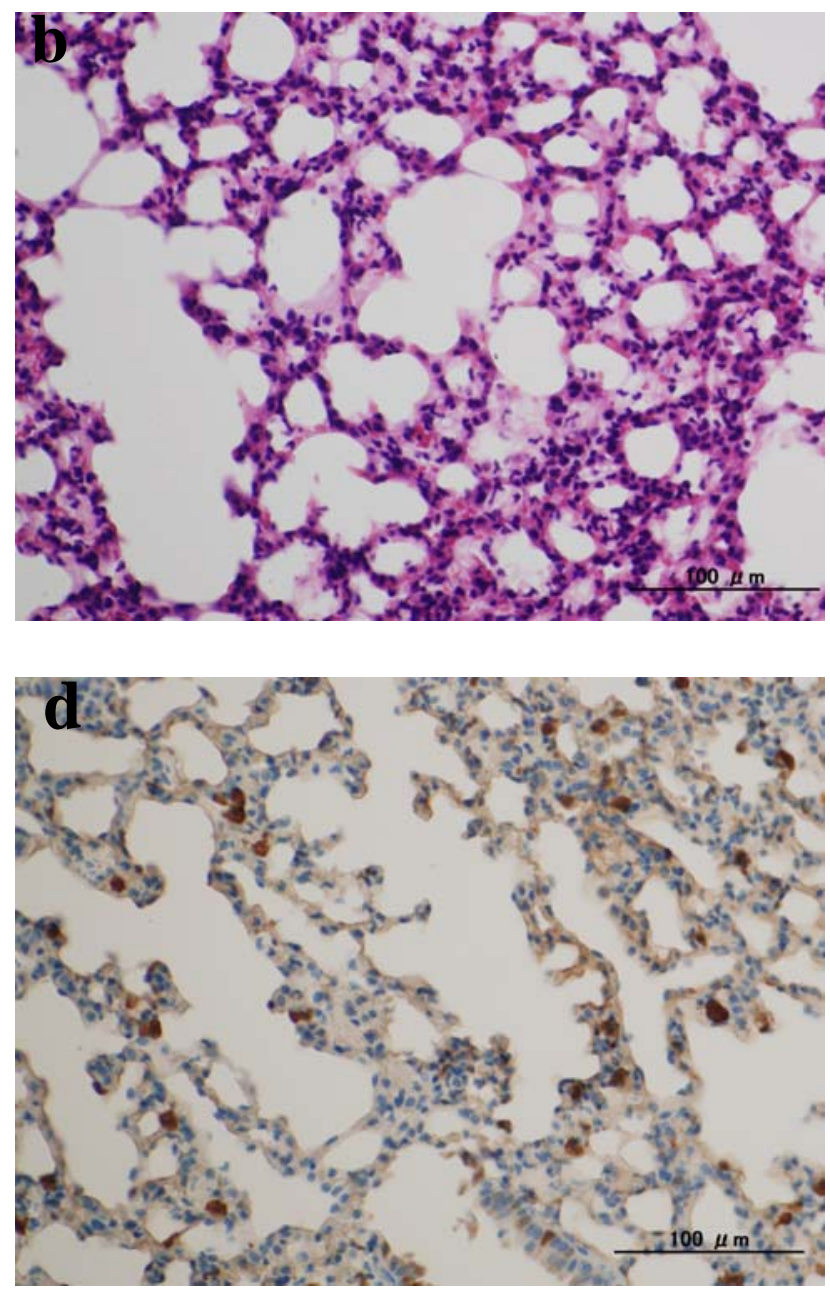

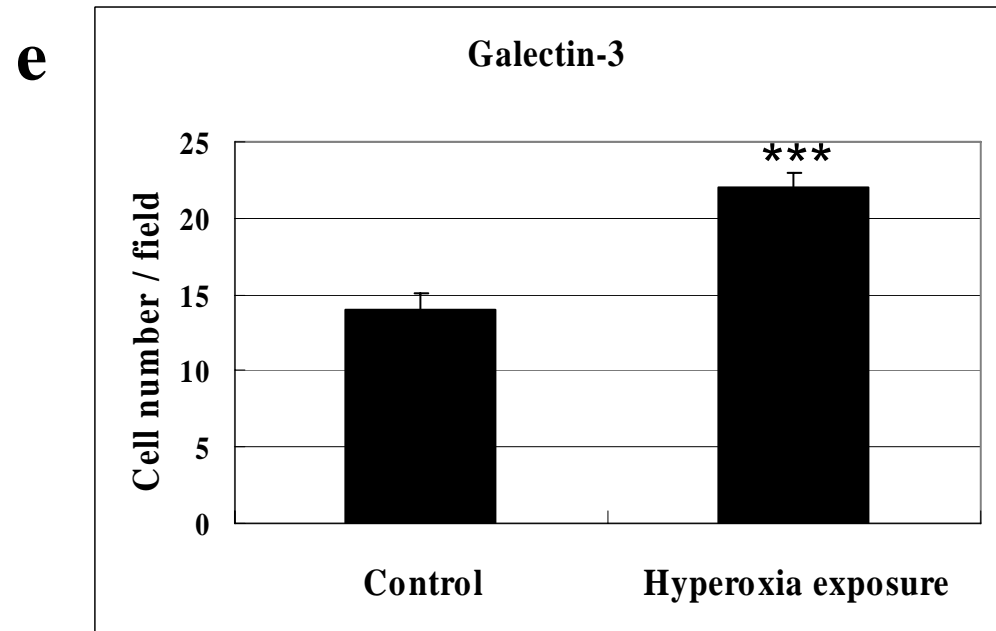

Fig. 1 

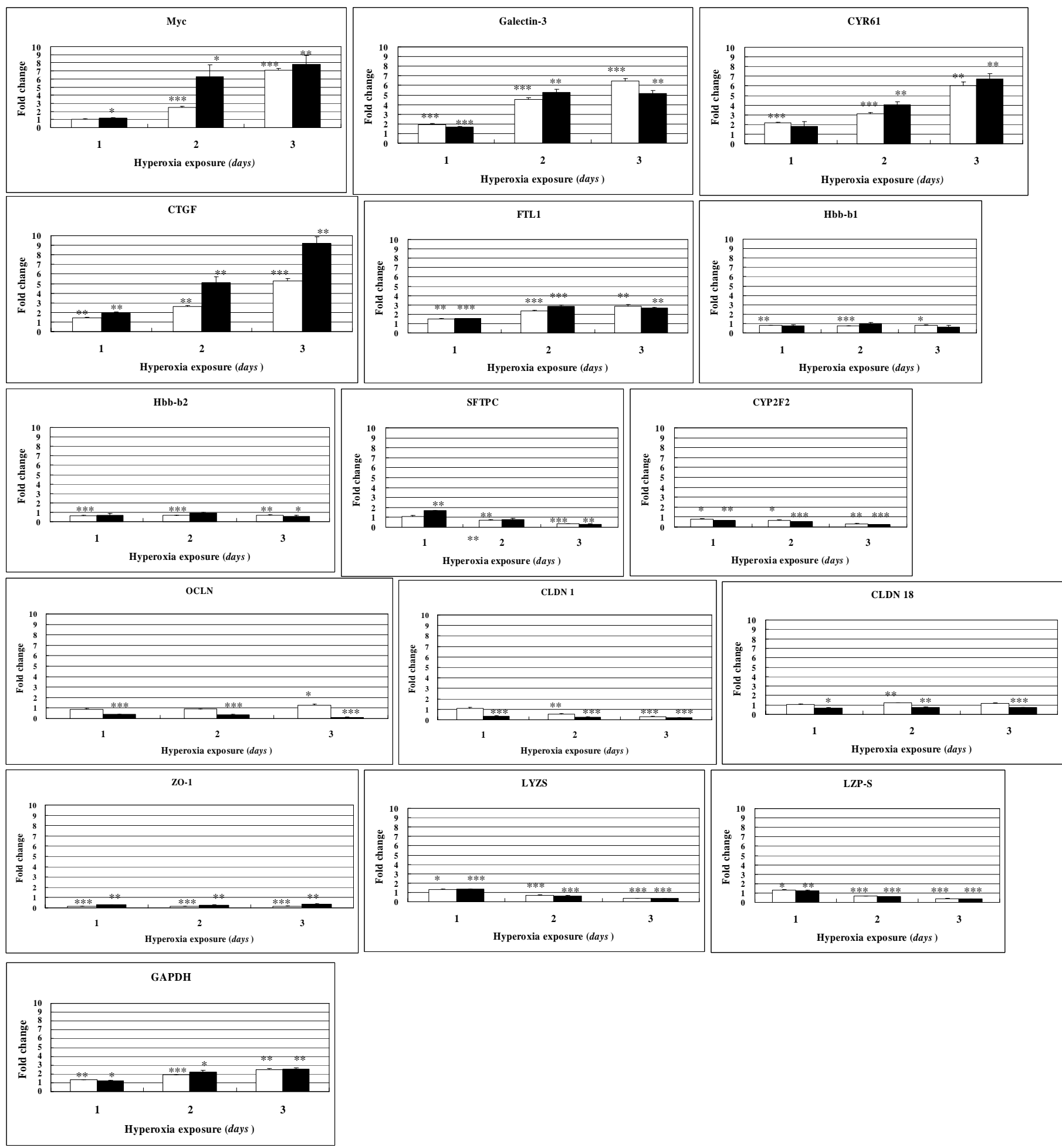

Fig. 2 

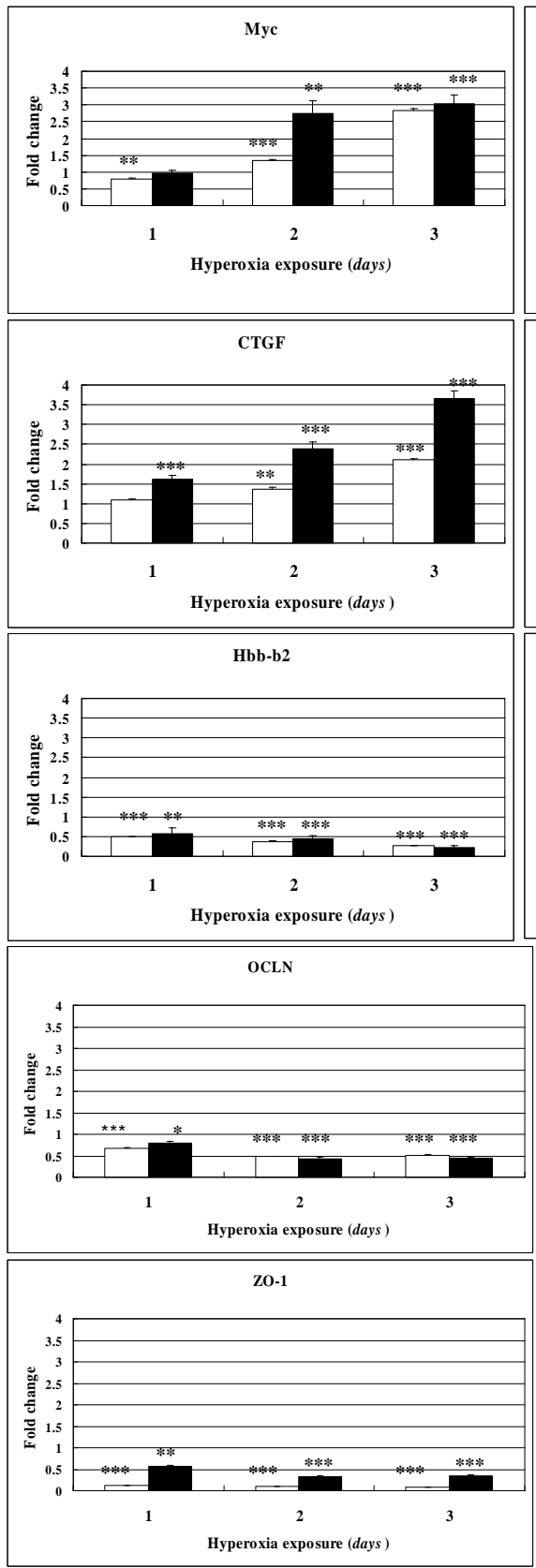
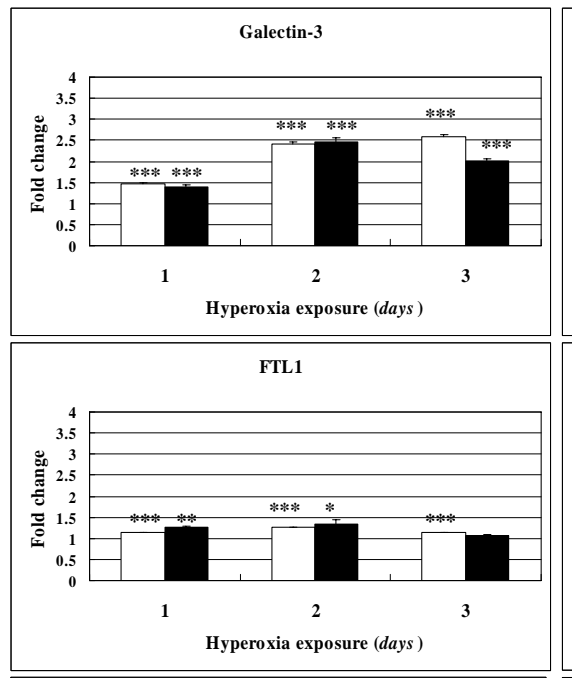

SFTPC
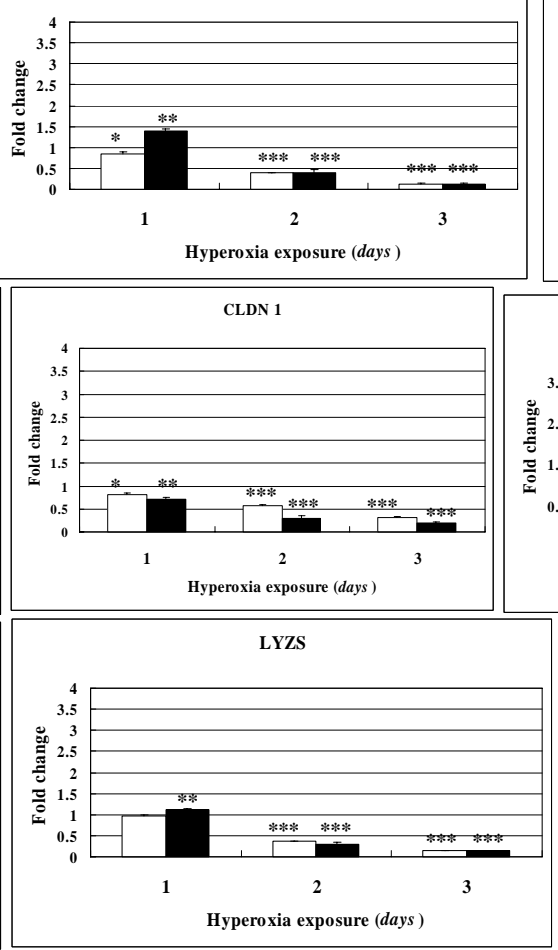
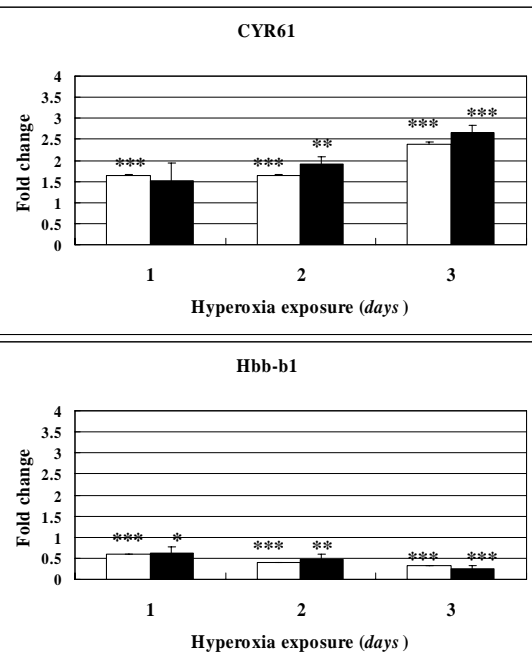

CYP2F2

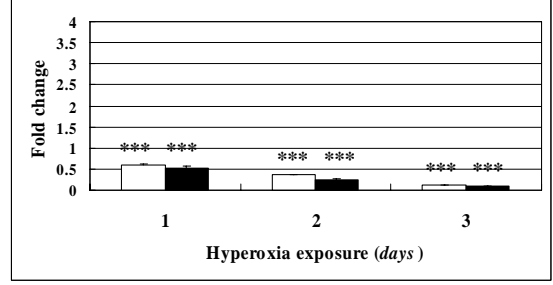

CLDN 18

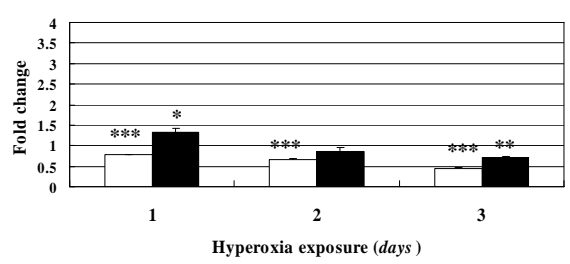

LZP-S

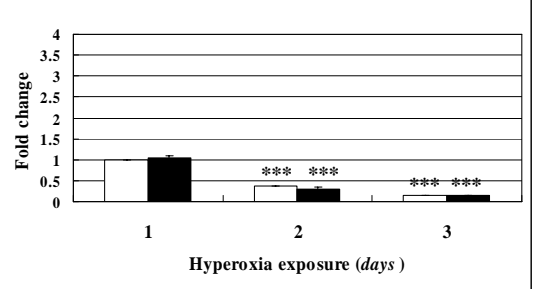


Table 1 Nucleotide sequences of primers for real-time qPCR assay

\begin{tabular}{|c|c|c|c|c|c|}
\hline Gene symbol & GenBank accession no. & Orientation & Nucleotide sequence & Position, Size of the amplified & PCR product \\
\hline Мyc & NM_010849 & $\begin{array}{l}\text { Sense } \\
\text { Antisense }\end{array}$ & $\begin{array}{l}\text { 5'-GAACTTCACCAACAGGAACTATGAC-3' } \\
\text { 5'-GAATTTCTTCCAGATATCCTCACTG-3' }\end{array}$ & $\begin{array}{l}596-620 \\
740-716\end{array}$ & 145 bp \\
\hline Galectin-3 & NM_010705 & $\begin{array}{l}\text { Sense } \\
\text { Antisense }\end{array}$ & $\begin{array}{l}\text { 5'-CAACAGGAGAGTCATTGTGTGTAAC-3' } \\
\text { 5'-TTCAACCAGGACTTGTATTTTGAAT-3' }\end{array}$ & $\begin{array}{l}581-605 \\
698-674\end{array}$ & 118 bp \\
\hline CYR61 & NM_010516 & $\begin{array}{l}\text { Sense } \\
\text { Antisense }\end{array}$ & $\begin{array}{l}\text { 5'-AGACCCTGTGAATATAACTCCAGAA-3' } \\
\text { 5'-AATTGCGATTAACTCATTGTTTCTC-3' }\end{array}$ & $\begin{array}{l}481-505 \\
780-756\end{array}$ & 300 bp \\
\hline CTGF & NM_010217 & $\begin{array}{l}\text { Sense } \\
\text { Antisense }\end{array}$ & $\begin{array}{l}\text { 5'-CCAACTATGATGCGAGCCAACTGCC-3' } \\
\text { 5'-CCATCGGGGCATTTGAACTCCACTG-3' }\end{array}$ & $\begin{array}{l}790-814 \\
1145-1121\end{array}$ & 356 bp \\
\hline FTL1 & NM_010240 & $\begin{array}{l}\text { Sense } \\
\text { Antisense }\end{array}$ & $\begin{array}{l}\text { 5'-CGAATTGGCCGAGGAGAAGCGCGAG-3' } \\
\text { 5'-TAGTCGTGCTTGAGAGTGAGGCGCT-3' }\end{array}$ & $\begin{array}{l}364-388 \\
756-732\end{array}$ & 393 bp \\
\hline Hbb-b1 & NM_008220 & $\begin{array}{l}\text { Sense } \\
\text { Antisense }\end{array}$ & $\begin{array}{l}\text { 5'-GGTACTTTGATAGCTTTGGAGACCT-3' } \\
\text { 5'-CATCGTTAAAGGCAGTTATCACTTT-3' }\end{array}$ & $\begin{array}{l}178-202 \\
279-255\end{array}$ & 102 bp \\
\hline Hbb-b2 & NM_016956 & $\begin{array}{l}\text { Sense } \\
\text { Antisense }\end{array}$ & $\begin{array}{l}\text { 5'-ACTTGCAACTTCAGAAACAGACATC-3' } \\
\text { 5'-AGGTCTCCAAAGCTATCAAAGTACC-3' }\end{array}$ & $\begin{array}{l}10-34 \\
180-156\end{array}$ & 171 bp \\
\hline SFTPC & NM_011359 & $\begin{array}{l}\text { Sense } \\
\text { Antisense }\end{array}$ & $\begin{array}{l}\text { 5'-GCTCCAGGAACCTACTGCTACATCA-3' } \\
\text { 5'-AAGAATCGGACTCGGAACCAGTATC-3' }\end{array}$ & $\begin{array}{l}373-397 \\
535-511\end{array}$ & 163 bp \\
\hline CYP2F2 & NM_007817 & $\begin{array}{l}\text { Sense } \\
\text { Antisense }\end{array}$ & $\begin{array}{l}\text { 5'-GCTGATGACCACACACAACCTGCTC-3' } \\
\text { 5'-CTGAGGCGTCTTGAACTGGTCCGAG-3' }\end{array}$ & $\begin{array}{l}925-949 \\
1279-1255\end{array}$ & 355 bp \\
\hline OCLN & NM_008756 & $\begin{array}{l}\text { Sense } \\
\text { Antisense }\end{array}$ & $\begin{array}{l}\text { 5'-CTGCAGGAGTATAAGAGCTTACAGG-3' } \\
\text { 5'-TGCTTGCAGTAATTCCTCTTACTTT-3' }\end{array}$ & $\begin{array}{l}1494-1518 \\
1681-1657\end{array}$ & 188 bp \\
\hline CLDN1 & NM_016674 & $\begin{array}{l}\text { Sense } \\
\text { Antisense }\end{array}$ & $\begin{array}{l}\text { 5'-CAGTGGAAGATTTACTCCTATGCTG-3' } \\
\text { 5'-AATTAAAAATATTATGCCCCCAATG-3' }\end{array}$ & $\begin{array}{l}299-323 \\
598-574\end{array}$ & 300 bp \\
\hline CLDN18 & NM_019815 & $\begin{array}{l}\text { Sense } \\
\text { Antisense }\end{array}$ & $\begin{array}{l}\text { 5'-CAACTTCAAAGCTGTGTCTTACCAT-3' } \\
\text { 5'-ATCGTAGATCTTCTTGTTTCTGGTG-3' }\end{array}$ & $\begin{array}{l}688-712 \\
802-778\end{array}$ & 115 bp \\
\hline $\mathrm{ZO}-1$ & D14340 & $\begin{array}{l}\text { Sense } \\
\text { Antisense }\end{array}$ & $\begin{array}{l}\text { 5'-GTTGTGTTCCTTAACCCTGACTCTA-3' } \\
\text { 5'-TGTGAAGAGATGGTGATTGTTCTTA-3' }\end{array}$ & $\begin{array}{l}2576-2600 \\
2713-2689\end{array}$ & 138 bp \\
\hline LYZS & NM_017372 & $\begin{array}{l}\text { Sense } \\
\text { Antisense }\end{array}$ & $\begin{array}{l}\text { 5'-GGAATGGAATGGCTGGCTACTATGG-3' } \\
\text { 5'-TGCTCGAATGCCTTGGGGATCTCTC-3' }\end{array}$ & $\begin{array}{l}117-141 \\
400-376\end{array}$ & 284 bp \\
\hline LZP-S & NM_013590 & $\begin{array}{l}\text { Sense } \\
\text { Antisense }\end{array}$ & $\begin{array}{l}\text { 5'-CAGCATGAGAGCAATTATAACACAC-3' } \\
\text { 5'-ATATACTGGGACAGATCTCGGTTTT-3' }\end{array}$ & $\begin{array}{l}181-205 \\
458-434\end{array}$ & 278 bp \\
\hline GAPDH & M32599 & $\begin{array}{l}\text { Sense } \\
\text { Antisense }\end{array}$ & $\begin{array}{l}\text { 5'-GCCATCAACGACCCCTTCAT-3' } \\
\text { 5'-ATGATGACCCGTTTGGCTCC-3' }\end{array}$ & $\begin{array}{l}134-153 \\
402-383\end{array}$ & 269 bp \\
\hline
\end{tabular}


Table 2 Genes up-regulated in mice

\begin{tabular}{|c|c|c|c|c|c|}
\hline Gene name & Gene ontology & GenBank accession no. & Ratio 1 & Ratio 2 & Mean \\
\hline cysteine rich protein 61 (Cyr61) & growth factor-binding protein, angiogenesis & NM_010516 & 4.00 & 3.46 & 3.73 \\
\hline ferritin light chain 1 (Ftl1) & iron ion homeostasis & NM_010240 & 2.66 & 2.00 & 2.33 \\
\hline connective tissue growth factor (Ctgf) & fibroblast proliferation, angiogenesis & NM_010217 & 2.44 & 1.89 & 2.16 \\
\hline actin, gamma, cytoplasmic 1 (Actg1) & actin cytoskeleton, sarcomere organization & NM_009609 & 1.48 & 2.16 & 1.82 \\
\hline solute carrier family 3, member 2 (Slc3a2) & cell-surface antigen & NM_008577 & 1.49 & 1.75 & 1.62 \\
\hline \multicolumn{6}{|l|}{ Table 3 Genes down-regulated in mice } \\
\hline Gene name & Gene ontology & GenBank accession no. & Ratio 1 & Ratio 2 & Mean \\
\hline hemoglobin, beta adult minor chain (Hbb-b2) & oxygen and carbon dioxide transport & NM_016956 & 0.3 & 0.38 & 0.34 \\
\hline hemoglobin, beta adult major chain (Hbb-b1) & oxygen and carbon dioxide transport & NM_008220 & 0.35 & 0.33 & 0.34 \\
\hline surfactant-associated protein C (Sftpc) & alveolar stability & NM_011359 & 0.41 & 0.34 & 0.37 \\
\hline P lysozyme structural (Lzp-s) & cell wall catabolism, bacteriolytic function & NM_013590 & 0.51 & 0.25 & 0.38 \\
\hline lysozyme (Lyzs) & cell wall catabolism, bacteriolytic function & NM_017372 & 0.49 & 0.32 & 0.4 \\
\hline cytochrome P450, 2f2 (Сyp2f2) & oxydization of naphthalene, electron transport & NM_007817 & 0.46 & 0.38 & 0.42 \\
\hline RIKEN cDNA 1810057C19 gene (1810057C19Rik) & Unknown & NM_026433 & 0.4 & 0.47 & 0.43 \\
\hline stearoyl-Coenzyme A desaturase $1(\mathrm{Scd} 1)$ & fatty acid biosynthesis, superoxide metabolism & NM_009127 & 0.54 & 0.32 & 0.43 \\
\hline thioether S-methyltransferase (Inmt) & sulfur and selenium metabolism & NM_009349 & 0.44 & 0.48 & 0.46 \\
\hline RIKEN cDNA 2700055K07 gene (2700055K07Rik ) & Unknown & NM_026481 & 0.56 & 0.36 & 0.46 \\
\hline myosin, light polypeptide 4 (Myl4) & structural constituent of muscle, muscle contraction & NM_010858 & 0.49 & 0.47 & 0.48 \\
\hline selenium binding protein 2 (Selenbp2) & selenium and acetaminophen binding & NM_019414 & 0.48 & 0.53 & 0.51 \\
\hline ATPase, $\mathrm{Ca}^{2+}$ transporting, cardiac muscle, slow twitch 2 (Atp2a2) & contractile function & NM_009722 & 0.45 & 0.61 & 0.53 \\
\hline haptoglobin (Hp) & hemoglobin binding, acute-phase response & NM_017370 & 0.47 & 0.59 & 0.53 \\
\hline sodium/hydrogen exchanger, isoform 3 regulator 2 (Slc9a3r2) & transepithelial sodium absorption & NM_023055 & 0.6 & 0.49 & 0.54 \\
\hline elongation of very long chain fatty acids -like 1 (Elovl1) & elongation of very long chain fatty acids & NM_019422 & 0.58 & 0.51 & 0.55 \\
\hline DNA segment, Chr 4 (D4Wsu53e) & nucleic acid binding & NM_023665 & 0.56 & 0.55 & 0.55 \\
\hline stearoyl-Coenzyme A desaturase 2 (Scd2) & fatty acid biosynthesis, superoxide metabolism & NM_009128 & 0.59 & 0.52 & 0.55 \\
\hline aquaporin 1 (Aqp1) & water transport, integral to plasma membrane & NM_007472 & 0.54 & 0.6 & 0.57 \\
\hline carbonic anhydrase 3 (Car3) & carbonate dehydratase activity, high concentration in muscle & NM_007606 & 0.6 & 0.57 & 0.59 \\
\hline fatty acid binding protein 4 , adipocyte (Fabp4) & fatty acid binding, cholesterol homeostasis & NM_024406 & 0.64 & 0.54 & 0.59 \\
\hline cysteine rich protein 2 (Crip2) & hemopoiesis, positive regulation of cell proliferation & NM_024223 & 0.65 & 0.56 & 0.6 \\
\hline opioid growth factor receptor (Ogfr) & opioid receptor activity, modulation of cell proliferation & NM_031373 & 0.65 & 0.56 & 0.6 \\
\hline thyroid hormone responsive SPOT14 homolog (Rattus) (Thrsp) & lipogenesis & NM_009381 & 0.65 & 0.57 & 0.61 \\
\hline dynein, cytoplasmic, light chain 1 (Dnclc1) & protein inhibitor of neuronal NOS, actin filament organizaion & NM_019682 & 0.64 & 0.6 & 0.62 \\
\hline receptor (calcitonin) activity modifying protein 2 (Ramp2) & G-protein coupled receptor protein signaling pathway & NM_019444 & 0.65 & 0.63 & 0.64 \\
\hline transmembrane protein 59 (Tmem59) & Unknown & NM_029565 & 0.66 & 0.63 & 0.65 \\
\hline forkhead box G1 (Foxg1) & forebrain development, ganglia morphogenesis & NM_008241 & 0.65 & 0.66 & 0.65 \\
\hline RIKEN cDNA 2410005016 gene (2410005O16Rik) & Unknown & NM_025476 & 0.66 & 0.67 & 0.67 \\
\hline
\end{tabular}

